\title{
Nucleic acids in disease and disorder: Understanding the language of life emerging from the ' $\mathrm{ABC}$ ' of DNA
}

'Albany 2011: Conversation 17' was held in June 2011 at SUNY, Albany - a remarkable gathering in a series organized by Prof Ramaswamy Sarma since the first meeting held 39 years ago at SUNY, Albany. As with all Albany gatherings, the 17th Conversation had several elements of excitement in the discussions on biomolecular structure and dynamics (Sarma 2011a). The three of us, along with few other young researchers including doctoral students from various organizations, were representing India.

One of the highlights of the 17th Conversation was the Beveridge celebration - to celebrate the achievements of the living legend Prof David Beveridge, a pioneer in computational biology, DNA structure and dynamics in particular. One of Beveridge's major contributions has been the monumental effort of setting up of the Ascona B-DNA Consortium (ABC) - a global collection of scientists working with a focus on an identified aspect of computationally understanding DNA structure and dynamics. This concept has been extremely successful in solving large computational problems, overcoming the limited computing capacities available with individual researchers, by dividing the problems into smaller sets that can be solved using local computing resources. It has not only 'networked' independent computing environments, but has created a growing global collaborative setup for research (Beveridge et al. 2012).

India has had, and continues to have, a rich history of contributions in the field of protein structure and dynamics, from collagen work of Ramachandran with Gopinath Kartha (Ramachandran and Kartha 1954) and subsequently Manju Bansal (Bansal et al. 1975; Bansal 1977), to crystallographic works of Vijayan and colleagues (Banerjee et al. 1994), to the more recent work of Mittal and Jayaram (Mittal et al. 2010; Mittal and Jayaram 2011a, b; Sarma 2011b) - a testament to which are the ongoing and planned Golden Jubilee celebrations for Prof GN Ramachandran's seminal work on protein conformations (Ramachandran et al. 1963). A somewhat lesser appreciated fact in the Indian scientific community, however, is the role of Indian scientists, again initiated by Ramachandran's group (Sasisekharan et al. 1981), in contributing towards developing our current understanding of DNA structure (Jayaram et al. 1989; Jayaram and Beveridge 1990; Mohanty and Bansal 1995; Young et al. 1997; Madhumalar and Bansal 2003). Somehow this has led to a slower growth in the number of researchers in India being interested in, and contributing towards, understanding the structure and dynamics of nucleic acids compared to the exponential increase in researchers working on protein structure and dynamics. In fact, the DNA community in India is relatively quite small, and has not met in years for a focused discussion evidenced by the fact that most young researchers in India are not aware that first discoveries of the lefthanded DNA structure, while being simultaneously explored by American scientists, happened in India in the late 1970s (Gupta et al. 1980; Bansal and Sasisekharan 1986). Further, several early efforts towards exploring structure and dynamics of nucleic acids (Jayaraman and Yathindra 1981; Maiti et al. 1983; Malathi and Yathindra 1985; Maiti and Nandi 1986; Santhosh and Mishra 1990; Hosur et al. 1990; Kumar et al. 1991) have not been followed up. More recently, while contributions such as NuParm (Bansal et al. 1995), Chemgenome (Dutta et al. 2006), PreDDicta (Shaikh and Jayaram 2007) and PROMBASE (Rangannan and Bansal 2011) have been received well internationally, they are yet to percolate into the Indian scientific community. Essentially there is a requirement to enthuse bright young investigators in India to pursue research in structural and functional aspects of nucleic acids.

Thus, an idea was mooted to host the next ABC meeting at IIT Delhi. The essential goal was to gather Indian scientists working on the structure and dynamics of nucleic acids and to provide a platform to invoke interest in young researchers. A key element was to also try to highlight the importance and imperative requirement of creating a collaborative network inspired by the success of $\mathrm{ABC}$, especially within the 
Indian scientific community. A perfect avenue for executing the above plan was provided by the newly established Kusuma School of Biological Sciences at IIT Delhi. Thus evolved an international conference on 'Nucleic acids in disease and disorder', organized by the Kusuma School of Biosciences in association with Supercomputing Facility for Bioinformatics \& Computational Biology, from 7 to 9 December 2011 at IIT Delhi. The programme provided an excellent opportunity to the students and the scientific community to discuss the latest developments in the diverse issues pertaining to the structure, dynamics, stability, interaction and function of nucleic acids.

The speakers' list included Prof David Beveridge (ABC of DNA; Beveridge et al. 2012); Tom Cheatham (Assessment and validation of MD simulations on nucleic acids); Mihaly Mezei (DNA solvation; Dixit et al. 2012); Manju Bansal (Structural and energetic approaches to genomic analyses; Kumar and Bansal 2012); Seyed Hasnain (Genomics of tuberculosis); Garima Khandelwal (Generating physicochemical finger prints for functional units on genomic DNA based on MD trajectories; Khandelwal et al. 2012); Dhananjay Bhattacharyya (Understanding of melting of polymeric DNA using MD simulations; Kundu et al. 2012); Prabal Maiti (MD simulations on DNA nanostructures; Nandy et al. 2012), Dipak Dasgupta (Interaction of small transcription inhibitors with genomic DNA; Dasgupta et al. 2012); D Sundar (DNA recognition by zinc finger proteins; Roy et al. 2012); Nirotpal Mrinal (Regulation of gene expression), Nidhi Jain (Sequence effects on conformational heterogeneity of DNA); Sanjay Kumar (Driven DNA); Vibha Tandon (Modulation of PNA-DNA interactions; Singh et al. 2012); NR Jena (DNA damage by reactive species; Jena 2012); MR Rajeswari (DNA triplexes in disease; Rajeswari 2012); Pradipta Bandyopadhyay (Monte Carlo simulations on RNA hairpins; Shanker and Bandyopadhyay 2012); G Suresh Kumar (RNA targeting by small molecules; Kumar 2012); Abhijit Mitra (Protonated base pairs in functional RNAs); Suhas Vasikar (Gene networks in neurodegenerative disorders); Khushhali Menaria (Genome to Hit pathway in silico); Surat Kumar (NMR in DNA-based drug design; Kumar et al. 2012); and K Muniappa (Homologous recombination in mycobacteria). The conference also witnessed 30 poster presentations by students and many lively discussions (Singh and Shah 2012; Mittal and Jayaram 2012). About 150 participants from all over India, in addition to the distinguished speakers from abroad, attended the meeting.

The editors of the Journal of Biosciences have kindly consented to bring out the proceedings of the conference as a special issue. This volume is a culmination of these events.

\section{References}

Banerjee R, Mande SC, Ganesh V, Das K, Dhanaraj V, Mahanta SK, Suguna K, Surolia A and Vijayan M 1994 Crystal structure of peanut lectin, a protein with an unusual quaternary structure. Proc. Natl. Acad. Sci. USA 91 227-231

Bansal M 1977 Stereochemical restrictions on the occurrence of amino acid residues in the collagen structure. Int. J. Pept. Prot. Res. $9224-233$

Bansal M and Sasisekharan V 1986 Molecular model-building of DNA: Constraints and restraints; in Theoretical chemistry of biological systems (ed) Naray-Szabo (Amsterdam: Elsevier Scientific Publishing Co.) pp127-218

Bansal M, Ramakrishnan C and Ramachandran GN 1975 A triple-helical model for (Gly-Pro-Hyp)n with cis peptide units. Biopolymers 14 2457-2466

Bansal M, Bhattacharyya D and Ravi B 1995 NUPARM and NUCGEN: Software for Analysis and generation of sequence dependent nucleic acid structures. CABIOS 11 281-287

Beveridge DL, Cheathem TE III and Mezei M 2012 The ABCs of molecular dynamics simulations on B-DNA, circa 2012. J. Biosci. 37 379-397

Dasgupta D, Majumder P and Banerjee A 2012 A revisit of the mode of interaction of small transcription inhibitors with genomic DNA. J. Biosci. 37 475-481

Dixit SB, Mezei M and Beveridge DL 2012 Studies of base pair sequence effects on DNA solvation based on all-atom molecular dynamics simulations. J. Biosci. 37 399-421

Dutta S, Singhal P, Agrawal P, Tomer R, Kritee, Khurana E and Jayaram B 2006 A Physico-chemical model for analyzing DNA sequences. J. Chem. Inf. Model. 46 78-85

Gupta G, Bansal M and Sasisekharan V 1980 Conformational flexibility of DNA: Polymorphism and handedness. Proc. Natl. Acad. Sci. USA 77 6486-6490 
Hosur RV, Chary KV, Saran A, Govil G and Miles HT 1990 Determination of solution conformation of DNA backbone: application of homonuclear (J, delta) spectroscopy. Biopolymers 29 953-959

Jayaram B and Beveridge DL 1990 Free energy of an arbitrary charge distribution imbedded in coaxial cylindrical dielectric continua: application to conformational preferences of DNA in aqueous solutions. J. Phys. Chem. 94 4666-4671

Jayaram B, Sharp KA and Honig B 1989 The electrostatic potential of B-DNA. Biopolymers 28 975-993

Jayaraman S, Yathindra N 1981 Analysis of possible helical structures for poly(dinucleotides) - Evidence for lefthanded Z-DNA and Z-type helices. Curr. Sci. 50 54-61

Jena NR 2012 DNA Damage by reactive species: Mechanisms, mutation and repair. J. Biosci. 37 503-517

Khandelwal G, Gupta J and Jayaram B 2012 DNA energetics-based analyses suggest additional genes in prokaryotes. $J$. Biosci. 37 433-444

Kumar GS 2012 RNA targeting by small molecules: Binding of protoberberine, benzophenanthridine, and aristolochia alkaloids to various RNA structures. J. Biosci. 37 539-552

Kumar A and Bansal M 2012 Characterization of structural and free energy properties of promoters associated with Primary and Operon TSS in Helicobacter pylori genome and their orthologs. J. Biosci. 37 423-431

Kumar RA, Hosur RV and Govil G 1991 Torsion angle approach to nucleic acid distance geometry: TANDY. $J$. Biomol. NMR 1 363-378.

Kumar S, Pandya P, Pandav K, Gupta SP and Chopra A 2012 Structural studies on the ligand-DNA systems: A robust approach in drug design. J. Biosci. 37 553-561

Kundu S, Mukherjee S and Bhattacharyya D 2012 Effect of temperature on DNA double helix: An insight from molecular dynamics simulation. J. Biosci. 37 445-455

Madhumalar A and Bansal M 2003 Structural insights into effect of hydration and ions on Atract DNA - A molecular dynamics study. Biophys. J. 85 1805-1816

Maiti M and Nandi R $1986 \mathrm{pH}$ induced change of natural deoxyribonucleic acids as followed by circular dichroism. Indian J. Biochem. Biophys. 23 322-325

Maiti M, Ghosh S, Chatterjee A and Chatterjee SN 1983 Thermal stability of DNA interacting with furazolidone and Cu (II) ions. Z Naturforsch C 38 290-293

Malathi R and Yathindra N 1985 Backbone conformation in nucleic-acids - An analysis of local helicity through heminucleotide scheme and a proposal for a unified conformational plot. J. Biomol. Struct. Dyn. 3 127-144

Mittal A and Jayaram B 2011a The newest view on protein folding: Stoichiometric and spatial unity in structural and functional diversity. J. Biomol. Struct. Dyn. 28 669-674

Mittal A and Jayaram B 2011b Backbones of folded proteins reveal novel invariant amino acid neighborhoods. $J$. Biomol. Struct. Dyn. 28 443-454

Mittal A and Jayaram B 2012 A possible molecular metric for biological evolvability. J. Biosci. 37 573-577

Mittal A, Jayaram B, Shenoy SR and Bawa TS 2010 A stoichiometry driven universal spatial organization of backbones of folded proteins: Are there Chargaff's rules for protein folding? J. Biomol. Struct. Dyn. 28 133-142

Mohanty D and Bansal M 1995 Chain folding and A:T pairing in human telomeric DNA: A model building and molecular dynamics study. Biophys. J. 69 1046-1067

Nandy B, Santosh M and Maiti PK 2012 Interaction of nucleic acids with carbon nano tubes and dendrimers. J. Biosci. $37457-474$

Rajeswari MR 2012 DNA triplex structures in neurodegenerative disorder, Friedreich's Ataxia. J. Biosci. 37 519-532

Ramachandran GN and Kartha G 1954 Structure of collagen. Nature 174 269-270

Ramachandran GN, Ramakrishnan C and Sasisekharan V 1963 Stereochemistry of polypeptide chain configurations. $J$. Mol. Biol. 7 95-99

Rangannan R and Bansal M 2011 PROMBASE: A web resource for various genomic features and predicted promoters in prokaryotic genomes. BMC Res. Notes 4257

Roy S, Dutta S, Khanna K, Shingla S and Sundar D 2012 Prediction of DNA-binding specificity in zinc finger proteins. J. Biosci. 37 483-491

Santhosh C and Mishra PC 1990 Spectroscopic evidence for structural oscillations in DNA caused by oxygen. Indian J. Biochem. Biophys. 27 209-212

Sarma RH (ed) 2011a Book of Abstracts: The 17th Conversation, Adenine Press, Schenectady NY, USA. J. Biomol. Struct. Dyn. 28 975-1164

Sarma RH 2011b A conversation on protein folding. J. Biomol. Struct. Dyn. 28 587-588

Sasisekharan V, Gupta G and Bansal M 1981 Sequence dependent molecular conformations of polynucleotides: Right and Left handed helices. Int. J. Biol. Macromol. $32-8$.

Shaikh SA and Jayaram B 2007 A Swift all-atom energy based computational protocol to predict DNA ligand binding affinity and $\Delta \mathrm{Tm} . J$. Med.Chem. 50 2240-2244

Shanker S and Bandyopadhyay P 2012 Determination of low-energy structures of a small RNA hairpin using Monte Carlo-based techniques. J. Biosci. 37 533-538 
Singh I and Shah K 2012 In silico study of interaction between rice proteins enhanced disease susceptibility and phytoalexin deficient regulators of salicylic acid signaling pathway. J. Biosci. 37 563-571

Singh N, Ranjan A, Sur S, Chandra R and Tandon V 2012 Inhibition of HIV-1 Integrase gene expression by 10-23 DNAzyme. J. Biosci. 37 493-502

Young MA, Jayaram B and Beveridge DL 1997 Intrusion of counterions into the spine of hydration in the minor groove of B-DNA: Fractional occupancy of electronegative pockets. J. Am. Chem. Soc. 119 59-69

\author{
MANJU BANSAL ${ }^{1}$, B JAYARAM ${ }^{2,3}$ and Aditya MitTAL ${ }^{2}$ \\ ${ }^{1}$ Molecular Biophysics Unit, Indian Institute of Science, Bangalore 560 012, India \\ ${ }^{2}$ Kusuma School of Biological Sciences, ${ }^{3}$ Department of Chemistry and Supercomputing Facility \\ for Bioinformatics \& Computational Biology, Indian Institute of Technology Delhi, \\ New Delhi 110 016, India
}

Corresponding authors (MB - Fax, 91-80-2360 0535; E-mail: mb@mbu.iisc.ernet.in; BJ-Fax, 91-11-26582037; E-mail: bjayaram@chemistry.iitd.ac.in; AM-Fax, 91-11-26582037; E-mail: amittal@bioschool.iitd.ac.in) 